\title{
KERAGAMAN SERANGGA PADA TANAMAN CABAI (CAPSICUM ANNUUM) YANG DIBERI PESTISIDA SINTETIS VERSUS BIOPESTISIDA RACUN LABA-LABA (NEPHILA SP.)
}

\author{
Yayan Sanjaya $^{1} \&$ Anna L.H. Dibiyantoro ${ }^{2}$ \\ ${ }^{1}$ Program Studi Biologi, Universitas Pendidikan Indonesia \\ E-mail: yayan229@yahoo.com \\ ${ }^{2}$ Balai Penelitian Tanaman Sayuran, Lembang
}

\begin{abstract}
Insect diversity in chili plants (Capsicum annum) treated with synthetic pesticide and biopesticide (venom of spider Nephila sp.). The objective of this research was to compare the diversity of insects in chili plant agroecosystem treated with synthetic pesticide versus that treated with biopesticide (venom of spider Nephila sp.) Two plots of chili pepper plants, each sized $600 \mathrm{~m}^{2}$, located at Ciwidey area Bandung -West Java, were taken as the sample plots. The first plot was weekly treated with profenofos insecticide ( $50 \%$ active ingredient, a.i.) while the second plot was treated with biopesticide (70\% a.i. spider venom extracted from Nephila sp.), each at $35 \mathrm{ml} / 17 \mathrm{~L}$ rate of spray solution. Sweep net was used to sample insects along two transects in each plot. Result showed that 14 families of 8 insect orders were found in pesticide-treated plot while 15 families of 9 orders were found in biopesticide-treated plot. The evenness index and diversity index of insects in plot treated with biopesticide were relatively higher than those in pesticide-treated plot. In contrast, dominance index in biopesticide plot was lower than that in synthetic pesticide plot. Thrips sp.(Thysanoptera: Thripidae) was found to be the most dominant species in both plots.
\end{abstract}

Key words: Capsicum annuum, venom of spider Nephila sp., synthetic pesticide, insect diversity

\begin{abstract}
ABSTRAK
Keragaman serangga pada tanaman cabai (Capsicum annuum) yang diberi pestisida sintetis versus biopestisida racun labalaba (Nephila sp). Pengamatan dilakukan dengan metode relatif (sweeping net dan visual). Dari hasil penelitian dapat diketahui tentang kekayaan taksa, kesamarataan, keragaman, dominansi dan kelimpahan relatifnya. Berdasarkan kekayaan taksanya ditemukan 14 famili serangga pada tanaman cabai yang diberi pestisida sintetis sedangkan pada tanaman cabai yang diberi biopestisida ada 15 famili serangga. Indeks Evenness dan indeks keragaman pada pertanaman cabai yang diberi biopestisida relatif lebih besar dibandingkan dengan di tanaman cabai yang diberi pestisida sintetis. Nilai indeks dominansi di pertanaman cabai yang diberi biopestisida relatif lebih rendah dibandingkan dengan di tanaman cabai yang diberi pestisida sintetis. Dari hampir setiap pengamatan Thrips sp. merupakan spesies dominan pada kedua pertanaman cabai.
\end{abstract}

Kata kunci: Capsicum annuum, biopestisida racun laba-laba (Nephila sp.), pestisida sintetis, keragaman serangga

\section{PENDAHULUAN}

Informasi dan teknik merupakan pondasi dalam membangun suatu program manajemen hama. Informasi yang penting antara lain (1) informasi biologis yang meliputi data tentang cara hama makan, tumbuh, berkembang, berproduksi, dan menyebar serta habitat yang dibutuhkan, (2) dinamika populasi yang dikaitkan dengn musuh alami, cuaca, makanan, dan habitat. Teknik yang menjadi dasar antara lain identifikasi spesies, pemeliharaan dan pencuplikan (Pedigo, 1999).

Adanya dampak negatif dari penggunaan insektisida, maka diperlukan adanya insektisida yang ramah lingkungan seperti insektisida yang berasal dari senyawa bioaktif yang berasal dari tumbuhan atau hewan. Senyawa bioaktif pada umumnya bersifat racun. Racun hewan berfungsi untuk melindungi diri dari musuh alami dan melumpuhkan mangsa, seperti halnya racun laba-laba. Foelix (1996) menyatakan bahwa racun labalaba memiliki fungsi primer yaitu melumpuhkan mangsanya dan fungsi sekunder yaitu mematikan mangsanya. Mangsa atau makanan utama laba-laba adalah serangga yang terperangkap dalam jaringnya (Tan, 2001). Laba-laba langsung melumpuhkan dan mematikan mangsanya dengan racunnya.

Berdasarkan hal-hal di atas, racun laba-laba memiliki potensi untuk di jadikan sebagai biopestida. Keuntungan lainnya adalah bahwa racun laba-laba 
merupakan biopestisida yang bersifat alami dan ramah lingkungan.

\section{METODE PENELITIAN}

Waktu dan Tempat. Penelitian ini dilakukan di Kecamatan Ciwidey Kabupaten Bandung pada bulan Februari- April 2010 pada lahan petani setempat. Luas lahan penelitian adalah $1600 \mathrm{~m}^{2}$.

Ekstraksi Racun Laba-laba Nephila sp. Ekstraksi racun laba-laba dilakukan berdasarkan metode Ori \& Ikeda (1998). Racun laba-laba diambil dari kelenjar racun di cephalothorax laba-laba Nephila sp. ditimbang seberat $1,5 \mathrm{~g}$. Racun laba-laba kemudian dihaluskan dengan penggiling mortar, lalu dilarutkan dlam $25 \mathrm{ml}$ etanol pro anlisis. Selanjutnya disimpan beberapa hari agar lautan mengendap, berikutnya adalah diambil bagian supernatnanya dan diencerkan hingga mengandung konsentrasi $75 \%$.

Penanaman Cabai (Capsicum annuum). Penanaman cabai dilakukan berdasarkan kebiasaan petani yaitu persiapan lahan dan penyemprotan pestisida dan biopestisida.

Persiapan Lahan. Pengolahan tanah (pencangkulan, pemerataan tanah), pembuatan lubang-lubang bertanam dengan tongkat dengan jarak tanam $50 \times 60 \mathrm{~cm}$, dengan sistem monokultur yaitu satu lubang satu tanaman, penyiapan benih dan pembibitan dilakukan di persemaian, benih cabai dikecambahkan terlebih dahulu, kemudian setelah beberapa hari (5-10 hari) dipindahkan kedalam bumbung (kokeran) yang terbuat dari daun pisang.Penanaman dilakukan dengan membuka kokeran. Kemudian dimasukkan ke dalam lubang tanam yang telah disiapkan di lapangan. Kedalaman pembenaman bibit dalam lubang tanam sebatas leher akar media semai, dan di kubur dengan tanah.

\section{Penyemprotan Pestisida dan Biopestisida.} Pestisida yang digunakan berbahan aktif profenofos 500 g/l. Penyemprotan pestisida dilakukan setiap satu kali seminggu, masing-masing lahan perlakuan diberikan 35 $\mathrm{ml}$ pestisida yang berbeda yaitu biopestisida dan pestisida sintetis untuk 17 liter air, penyemprotan dilakukan pagi hari setelah embun hilang.

Pengumpulan Data. Metode sampel yang digunakan adalah metode nisbi atau relatif. Langkah pertama adalah menentukan jalur pengambilan sampel dari masingmasing petak pertanaman cabai dengan luas $600 \mathrm{~m}^{2}$, yaitu mengambil sampel dua jalur secara horizontal, masing-masing satu balikan dengan metode relative sampling (Michael, 1984). Berikutnya mengambil sampel dengan cara mengayunkan sweep net dengan 10 kali ayunan sambil berjalan menuju ke titik berikutnya. Sweep net yang digunakan berdiameter mulut jaring 30 $\mathrm{cm}$, dengan panjang tangkai $1 \mathrm{~m}$ dan mempunyai ukuran mata jal 0,5 mm. Sebelumnya dilakukan studi pendahuluan untuk mendapatkan indeks presisi terkecil. Jaring diayunkan menyilang sepanjang jalur sampel (Michael, 1984). Pengamatan dilakukan sebanyak 8 kali. Serangga dari jaring diambil, dimatikan kemudian dimasukkan ke dalam botol koleksi. Setelah itu dilakukan identifikasi dan penghitungan (penurusan) jumlahnya. Data jumlah serangga digunakan untuk menentukan persentase kelimpahan realtif (KR), indeks keragaman Shannon Wiener, indeks dominansi Simpson dan indeks kesamarataan komunitas.

\section{HASIL DAN PEMBAHASAN}

Identifikasi Kelimpahan Relatif Serangga. Serangga yang diperoleh selama penelitian diidentifikasi berdasarakan Borror et al. (1992). Pengidentifikasian ini berguna untuk mengetahui kelompok dan peranannya terhadap tanaman cabai. Pada tanaman cabai yang diberi pestisida sintetis, jenis serangga yang ditemukan ada 14 famili, yang termasuk ke dalam 8 ordo. Sedangkan pada tanaman cabai yang diberi biopestisida, jenis serangga yang ditemukan ada 15 famili yang termasuk kedalam 9 ordo (Tabel 1).

Dilihat dari kekayaan famili terbanyak ditemukan pada kelompok tanaman cabai yang diberi biopestisioda yaitu sebanyak 15 famili dibandingkan dengan dengan diberi pestisida yaitu berjumlah 14 famili. Berdasarkan pengamatan serangga yang menguntungkan pada plot yang diberi perlakuan pestisida seperti pada Ordo Coleoptera, Hymenoptera dan Diptera pada pengamatan selanjutnya mengalami kematian.

Dengan mengetahui kekayaan serangga pada suatu tanaman, maka dapat memberikan harapan dalam menemukan spesies-spesies serangga predator dan parasitoid. Menurut Klowden (2007) serangga predator yaitu serangga yang memakan hewan atau serangga lain yang lebih kecil atau lebih lemah, baik seekor atau lebih dalam sekali makan. Berbeda dengan serangga predator, maka serangga parasitoid mempunyai inang yang khas. Mereka bertelur satu atau lebih pada tubuh inangnya, sehingga larva dari telur yang menetas sering kali merusak atau mematikan inangnya (Dibiyantoro, 1996). 
Tabel 1. Hasil identifikasi serangga dan penurusan kumulatif yang diperoleh dari tanaman cabai yang diberi pestisida dan biopestisida

\begin{tabular}{ccccc}
\hline \multirow{2}{*}{ No. } & & & & \\
& & Famili & \multicolumn{2}{c}{ Kelimpahan relatif $(\%)$} \\
\cline { 3 - 5 } & & & Pestisida & Biopestisida \\
\hline 1 & Diptera & Agromyzidae & 2,2 & 1,5 \\
& & Muscidae & 8,2 & 4,0 \\
& & Clusiidae & 0,2 & 0,1 \\
& & Tephritidae & 0,3 & 0,6 \\
2 & Lepidoptera & Pieridae & 0,2 & 0,1 \\
& & Noctuidae & 1,9 & 1,8 \\
3 & Thysanoptera & Thripidae & 75,6 & 80,4 \\
4 & Hemiptera & Pentatomidae & 0,2 & 0,1 \\
& & Cicadellidae & 0,2 & 0,1 \\
& & Aphididae & 9,4 & 8,2 \\
5 & Acari & Tetranychidae & 0,9 & 0,7 \\
6 & Orthoptera & Acrididae & 0,4 & 0,1 \\
7 & Hymenoptera & Braconidae & 0,0 & 1 \\
8 & Coleoptera & Staphylinidae & 0,2 & 1 \\
9 & Araneae & Lycosidae & 0,1 & 1 \\
\hline
\end{tabular}

Dari hasil penelitian ditemukan serangga predator dan parasitoid yang dapat diteliti efektifitasnya bagi usaha pengendalian serangga hama secara hayati. Pengendalian hama secara hayati ini berdasarkan prinsip bahwa di alam, rantai dan jaring-jaring makanan masih utuh, sehingga kestabilan populasi serangga merupakan hasil hubungan antara serangga hama dengan tumbuhan inangnya, serangga predator dan parasitoid sebagai musuh alami, dan faktor-faktor fisik lingkungan. Musuh alami sebagai pengatur dan pengendali populasi serangga hama, akan meningkat kegiatan memangsa dan populasinya jika populasi serangga hama yang menjadi mangsanya itu meningkat (Philip et al., 2011).

Kelimpahan juga berpengaruh terhadap diversitas karena kelimpahan merupakan salah satu faktor yang menentukan jumlah serangga. Selain itu, kelimpahan bersama-sama dengan distribusi ikut menentukan struktur komunitas yang menggambarkan bagaimana diversitas serangganya. Setiap serangga mempunyai kecenderungan yang berbeda dalam hal kelimpahan pada suatu habitat yang berhubungan dengan daya reproduksi dan adaptasi terhadap habitat yang cocok. Kelimpahan setiap jenis serangga dibatasi oleh faktorfaktor yang menentukan berapa banyak serangga tersebut (Hilje et al., 2003). Faktor tersebut mencakup sifat serangga itu sendiri dan sifat habitat atau lingkungannya. Kelimpahan tiap jenis serangga akan terus bertambah sampai tidak lagi tersedia cukup sumber makanan untuk mendu kung pertambahan individu, tanpa terlebih dahulu ada pengaruh predator, parasitoid, dan regulator.
Berdasarkan kelimpahannya, jenis- jenis serangga pada kelompok tanaman sayuran dapat dikelompokkan menjadi jenis dominan (KR>5\%), subdominan (KR 2$5 \%$ ), dan tidak dominan (KR 0-2\%). Jenis dominan ini lebih menunjukkan kepada kemampuan serangga untuk dapat beradaptasi terhadap lingkungannya dan kemampuan dalam mengendalikan ruang serta arus energi pada lingkungannya.

Dari keseluruhan pengamatan, tampak bahwa $T$. tabaci hampir disetiap pengamatan merupakan spesies yang dominan sepanjang hidup tanaman cabai. T. tabaci dapat mencapai kelimpahan yang sangat tinggi selama periode musim kering yang panjang. Kutu daun (Aphididae) mencapai kelimpahan yang sangat tinggi pada musim kemarau (Sosromarsono, 1993). Sedangkan spesies-spesies yang termasuk kedalam sub-dominan pada waktu pengamatan yaitu Liriomyza sp.

Kesamarataan. Kesamarataan dihitumg dengan indeks evenness dari Pielou (dalam Maguran \& Hall, 1988). Kesamarataan merupakan salah satu komponen diversitas yang menyatakan jumlah jenis dengan jumlah individu, dalam hal perataannya. Nilai yang diperoleh dari hasil penghitungan menunjukkan kesempatan yang dimiliki oleh masing-masing individu di dalam komunitas tersebut untuk dapat menjalankan fungsi-fungsi ekologisnya (herbivora, parasitoid, atau predator). Semakin tinggi nilai indeks ini, maka semakin sama kesempatan dari masing-masing jenis serangga dalam komunitas tersebut. Nilai kesamarataan (indeks 
evenness) dari hasil penelitian ditampilkan pada Gambar 1.

Berdasarkan Gambar 1 pada kelompok tanaman cabai yang diberi pestisida sintetis dan biopestisida mempunyai nilai indeks evenness yang berbeda. Pada kelompok tanaman cabai yang diberi biopestisida nilai indeks evenness cenderung lebih tinggi dibandingkan dengan kelompok tanaman cabai yang diberi pestisida sintetis. Hal ini menunjukkan bahwa kondisi lingkungan mempunyai hubungan dengan tingkat serangan oleh serangga. Pada kelompok tanaman cabai yang diberi biopestida nilai indeks Evenness yang lebih tinggi menunjukkan bahwa jenis-jenis serangga yang ada mempunyai kesempatan yang sama dalam memanfaatkan habitatnya, baik itu serangga hama, serangga parasitoid, serangga predator dan jenis serangga lainnya pada lingkungan ini. Jika kesempatan dalam memanfaatkan habitat bagi jenis-jenis serangga predator dan parasitoid dapat dioptimalkan, maka akan tercipta suatu kondisi yang memungkinkan jenis-jenis serangga predator dan parasitoid untuk berperan efektif di lingkungannya. Hal ini akan sangat membantu pemanfaatan serangga predator dan parasitoid untuk mengendalikan jenis-jenis serangga hama.

Gambar 1 juga menunjukkan bahwa terjadi peningkatan nilai indeks evenness (E) yang menunjukkan adanya hubungan antara umur tanaman dengan kesempatan yang dimiliki oleh setiap anggota komunitas untuk menjalankan fungsi-fungsi ekologisnya sejalan dengan penambahan umur dari tanaman dimana peningkatan nilai indeks evenness mengindikasikan peningkatan kesempatan bagi tiap-tiap spesies untuk dapat memanfaatkan relung-relung yang tersedia. Hal ini dapat terjadi dengan adanya perubahan dalam komposisi dari setiap spesies yang menempati komunitas tersebut karena nilai indeks evenness bergantung kepada nilai indeks Shannon Wiener yang menunjukkan tingkat keanekaragaman dari masing-masing spesies.

Perubahan dalam komposisi ini mungkin juga disebabkan karena terjadinya perubahan kondisi lingkungan disekitar komunitas. Pemberian pestisida sintetis akan meninggalkan residu di lingkungan sekitar komunitas tanaman cabai sehingga akan mengubah kondisi dari komunitas tersebut. Dengan adanya residu pestisida sintetis, terdapat kemungkinan bahwa serangga-serangga yang memiliki daya adaptasi rendah akan tersisihkan sehingga menyebabkan terjadinya perubahan jumlah masing-masing spesies dan berakibat terhadap kesempatan bagi tiap individu untuk dapat memanfaatkan relung yang ada karena adanya kemungkinan terjadinya kompetisi untuk memperebutkan relung yang ada.

Pada kelompok tanaman cabai yang diberi biopestisida kemungkinan yang terjadi berbeda dengan kelompok tanaman cabai yang diberi pestisida sintetis. Pada kelompok tanaman cabai yang diberi biopestisida

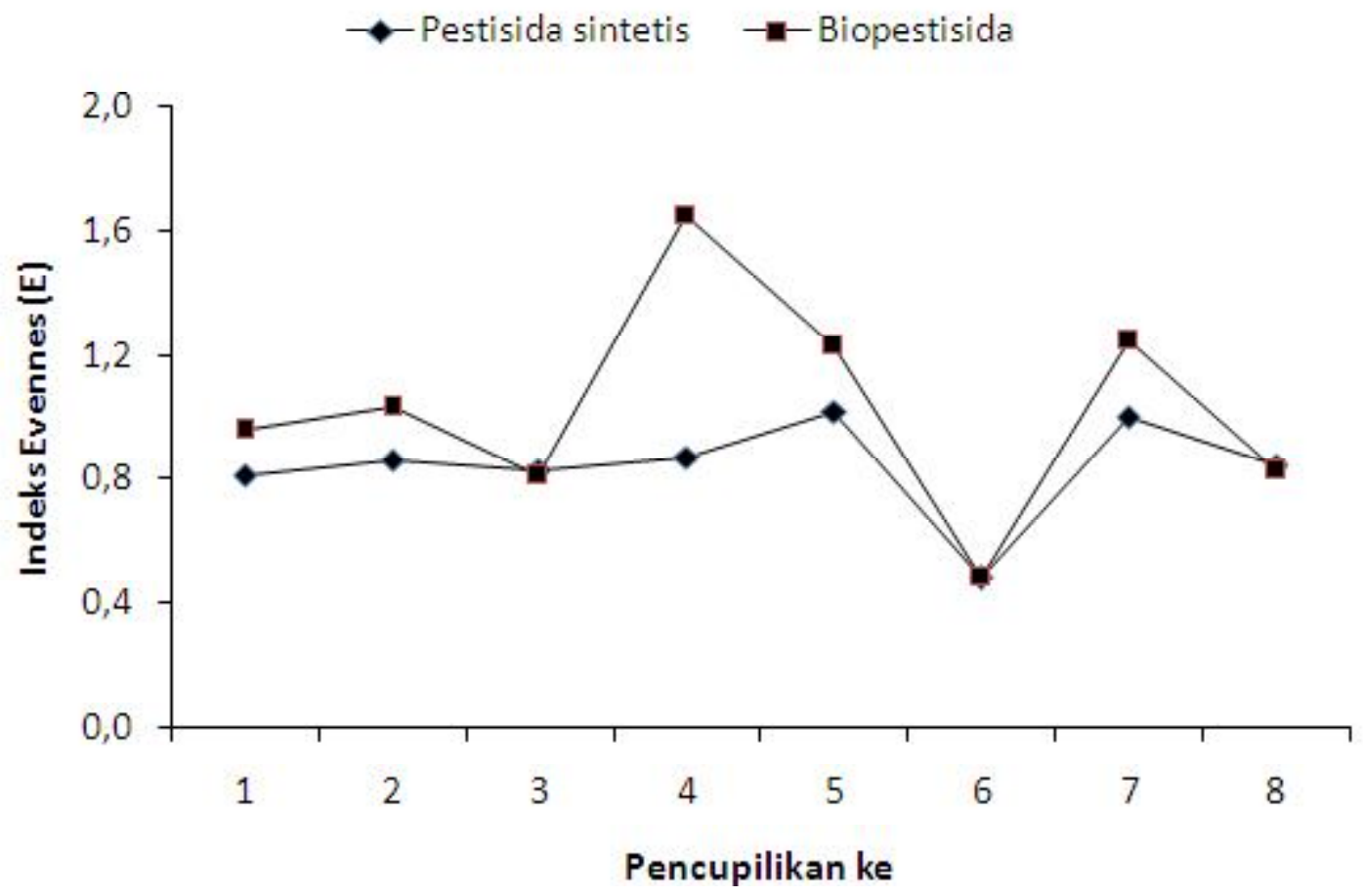

Gambar 1. Grafik fluktuasi indeks evenness (E) serangga pada kelompok tanaman cabai yang diberi pestisida sintetis dan biopestisida racun laba-laba (Nephila sp.). 
kemungkinan terjadinya residu sangat kecil karena sifat dari biopestisida yaitu membunuh hama pada waktu itu juga (Kardinan, 2002) sehingga kondisi lingkungan akan lebih stabil. Nilai indeks evenness dari komunitas ini mencapai nilai terbesar yaitu 1,22 dibandingkan dengan kelompok tanaman cabai yang diberi pestisida sintetis yang berarti tingkat kesamaan kesempatan bagi tiap individu yang terdapat pada ekosistem tersebut relatif lebih tinggi. Hal ini disebabkan karena adanya kesamaan daya saing dari spesis-spesies serangga baik itu seragga hama, serangga parasitoid ataupun serangga predator dalam memanfaatkan tanaman cabai ini sebagai makanan. Namun hasil analisis statistik diperoleh bahwa nilai indeks Evenness menunjukkan tidak berbeda nyata antar tanaman cabai yang diberi pestisida sintetis dan tanaman cabai yang diberi biopestisida. Keadaan ini berarti bahwa penggunaan biopestisida racun laba-laba Nephila sp. mampu menghasilkan nilai indeks Evenness yang sama bersama dengan pestisida sintetis.

Untuk tingkat kesamarataan dalam hal penyebaran jenis-jenis serangga, tertinggi terdapat pada kelompok tanaman cabai yang diberi biopestisida yaitu dengan nilai $\mathrm{E}=1,22$. Kondisi ini dapat terjadi karena banyak jenis serangga pada habitat ini yang mempunyai daya adaptasi yang tinggi dan lebih cocok dengan kondisi habitatnya (Michel, 1984), karena pola penyebaran berhubungan dengan daya adaptasi dan kondisi habitatnya.

Keragaman. Keragaman merupakan gabungan antara komponen varietas dan komponen kesamarataan sebagai satu indeks diversitas secara keseluruhan (Maguran \& Hall, 1988). Oleh karena itu, bila semakin besar jumlah individu setiap spesiesnya, maka nilai indeks diversitassnya akan semakin tinggi. Nilai indeks diversitass ini dihitung berdasarkan indeks Shannon Wiener (Cronquist, 1981).

Menurut Maguran \& Hall (1988) nilai indeks ini berkaitan dengan kondisi lingkungan dari komunitas tersebut. Indeks diversitas pada ekosistem yang secara fisik dikendalikan memiliki nilai yang rendah sedangkan pada ekosistem alami memiliki nilai yang tinggi. Berdasarkan kriteria indeks Shanon Wiener, nilai indeks diversitass dapat dikelompokkan menjadi tiga, yaitu:

$1 . H^{\prime}<1$ beerarti diversitas pada ekosistem sangat dipengaruhi oleh lingkungan

$2.1<\mathrm{H}^{\prime}<3$ berarti diversitas pada ekosistem cukup dipengaruhi oleh lingkungan

3.H'> 3 berarti diversitas tidak dipengaruhi lingkungan.

Dari kedua kelompok tanaman cabai yang diteliti, diperoleh data tentang nilai indeks diversitas serangga seperti pada Gambar 2.
Berdasarkan Gambar 2 terlihat bahwa nilai indeks diversitas serangga pada setiap pengamatan dikedua kelompok tanaman cabai yang diteliti tergolong masih rendah bila dibandingkan dengan indeks diversitas serangga pada ekosistem alamiah. Sebagaimana diketahui bahwa indeks diversitas serangga pada ekosistem yang secara fisik terkendali cenderung rendah, dan tinggi pada ekosistem alamiah (Odum, 1993). Pada ekosistem alamiah peluang nilai indeks diversitasnya dapat > 2 (Michael, 1984). Hal ini kemungkinan terjadi karena diversitas serangga pada kedua komunitas tanaman cabai yang diteliti telah berkurang akibat pengaruh lingkungan seperti pemupukan, penyemprotan pestisida sintetis dan aplikasi teknis pertanian lainnya.

Diversitas serangga pada kelompok tanaman cabai yang diberi pestisida sintetis pada pengamatan keempat dan ketujuh termasuk kategori cukup dipengaruhi oleh lingkungan karena mempunyai nilai indeks diversitass dimana $1<\mathrm{H}^{\prime}<3$ sedangkan pada pengamatan yang lainnya termasuk pada kategori sangat dipengaruhi oleh lingkungan karena mempunyai nilai indeks $H^{\prime}<1$. Pada kelompok tanaman cabai yang diberi biopestisida, pada pengamatan keempat dan kelima mempunyai nilai indeks $1<\mathrm{H}^{\prime}<3$ sehingga termasuk pada kategori cukup dipengaruhi oleh lingkungan sedangkan pada pengamatan yang lainnya termasuk pada kategori sangat dipengaruhi oleh lingkungan karena mempunyai nilai indeks $H^{\prime}<1$. Namun hasil analisis statistik diperoleh bahwa nilai indeks keragaman menunjukkan tidak berbeda nyata antar tanaman cabai yang diberi pestisida sintetis dan tanaman cabai yang diberi biopestisida. Keadaan ini berarti bahwa penggunaan biopestisida racun laba-laba Nephila $s p$. mampu menghasilkan nilai indeks keragaman yang sama bersama dengan pestisida sintetis.

Dengan mengetahui keragaman atau indeks Shannon Wiener maka akan dapat diketahui adanya pengaruh lingkungan pada komunitas yang diamati. Dengan demikian maka akan dapat diketahui pengaruh lingkungan yang dapat mengubah diversitas, sehingga degradasi di lingkungan agroekosistem cepat kita sadari, untuk segara kita tanggulangi.

Dari kedua kelompok tanaman cabai yang diamati ini, ternyata keragaman serangga tertinggi terdapat pada kelompok tanaman cabai yang diberi biopestisida dengan nilai indeks diversitasnya sebesar 1,64.

Dominansi. Dominansi spesies pada komunitas serangga yang diamati dihitung berdasarkan indeks dominansi Simpson (Simpson dalam Odum, 1993). Bila nilai indeks dominansi $<1$ maka spesies serangganya beranekaragam, sebaliknya bila nilai indeks dominansi 


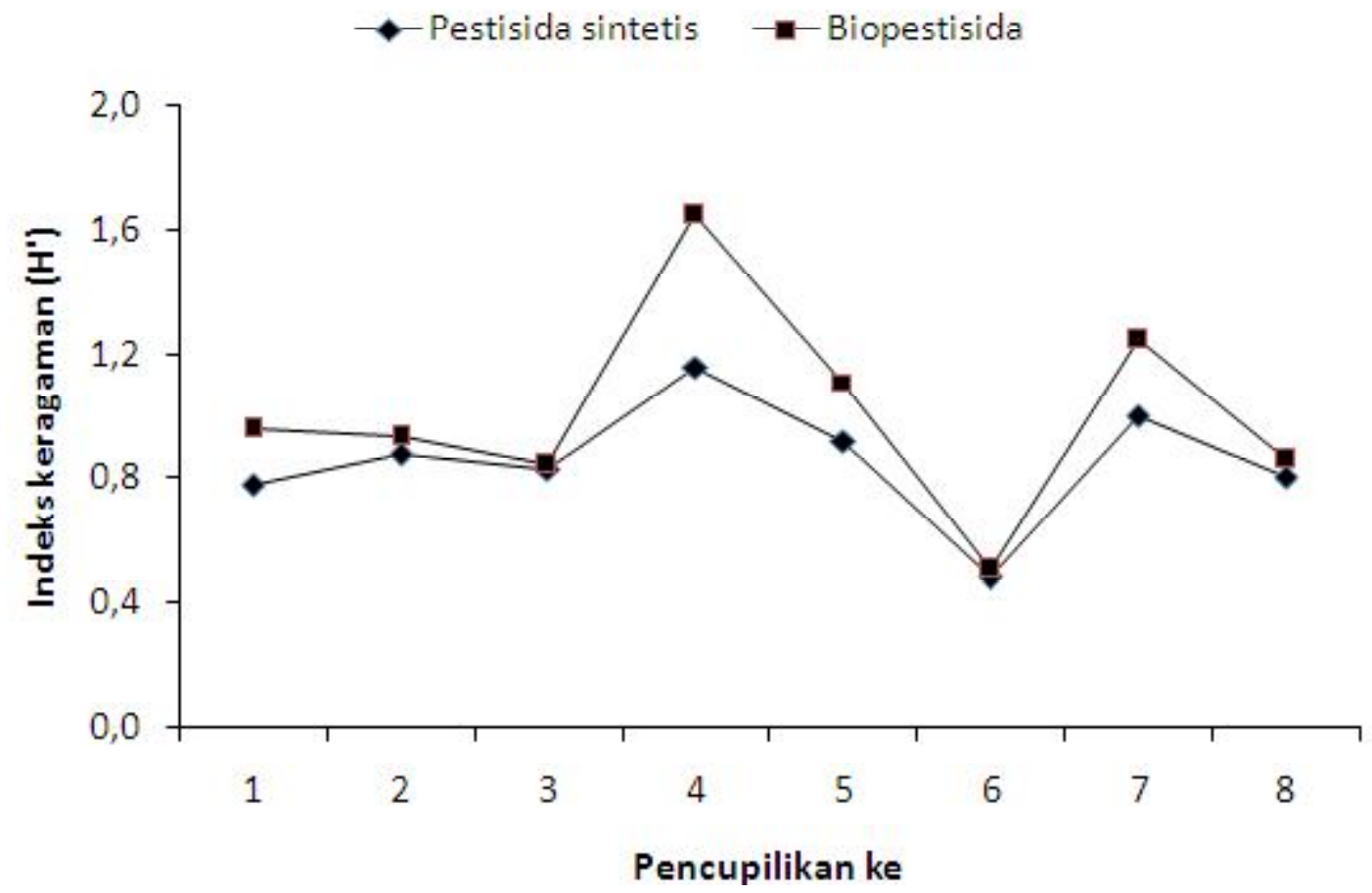

Gambar 2. Grafik Fluktuasi Indeks Keragaman (H') Serangga pada kelompok Tanaman Cabai yang Diberi Pestisida Sintetis dan Biopestisida Racun Laba-laba (Nephila sp.).

$=1$, maka spesies serangganya tidak beranekaragam. Selain itu, menurut perhitungan Simpson, bila nilai indeks Simpson (C) berkisar antara $0,7-0,8$ merupakan keadaan yang belum mengalami gangguan atau penceramaran, sedangkan bila $\mathrm{C}<0,7$ menunjukkan keadaan yang telah mengalami gangguan atau pencemaran. Indeks diversitas memberikan suatu cara terbaik untuk mengetahui dan menilai pencemaran. Adapun nilai indeks dominansi Simpson untuk kedua kelompok tanaman cabai yang diamati ditampilkan pada Gambar 3.

Dari Gambar 3 dapat dinyatakan bahwa dominansi yang tinggi tampak hanya terjadi pada pengamatan keenam dengan memperoleh nilai indeks dominansi Simpson lebih besar dari 0,7. Nilai tinggi ini tampaknya disebabkan kerena tingginya jumlah Thrips tabaci pada ekosistem tersebut (Gambar 3). Tetapi pada pengamatan yang lain nilai indeks dominansinya menjadi lebih kecil dari 0,7 hal ini disebabkan karena $T$. tabaci ini menghadapi suatu kondisi dimama terjadi persaingan baik secara intraspesies maupun interspesies. Persaingan ini selanjutnya menekan populasi T. tabaci dan menurunkan kemampuan spesies ini untuk mendominasi. Selain itu tampaknya pemberian pestisida sintetis juga memberikan tekanan kepada spesies ini sehingga nilai indeks Simpsonnya menjadi lebih rendah pada komunitas yang terdapat pada ekosistem tanaman cabai yang disemprot dengan pestisida sintetis.
Dari Gambar 3 terlihat bahwa pada pengamatan keenam mempunyai nilai indeks Simpson paling besar yang mencapai nilai diatas 0,7 . Nilai tinggi ini tampaknya disebabkan kerena tingginya jumlah $T$. tabaci pada ekosistem tersebut (Gambar 3). Tetapi pada pengamatan kedelapan mengalami penurunan. Penurunan yang terjadi tampaknya akibat menurunnya sumber daya yang dapat dimanfaatkan terutama makanan dan tempat berlindung. Kemampuan dominansi dari T. tabaci yang tinggi ini mungkin berkaitan dengan kurangnya tingkat pencemaran dan gangguan pada komunitas tersebut, karena pada komunitas tersebut hanya diberikan pestisida alami yang mempunyai sifat mudah diuraikan baik oleh sinar matahari, udara, kelembapan atau pun oleh komponen alam lainnya. Rendahnya nilai diversitas serangga secara langsung akan mengurangi terjadinya kompetisi interspesies yang dapat memicu munculnya dominansi dari satu spesies. Pada minggu keempat terjadi penurunan dominansi dari T. tabaci yang kemungkinan disebabkan oleh peningktan diversitas serangga yang ditunjukkan dengan peningkatan indeks Shannon Wiener (Gambar 2). Namun hasil analisis statistik diperoleh bahwa nilai indeks dominansi menunjukkan tidak berbeda nyata antar tanaman cabai yang diberi pestisida sintetis dan tanaman cabai yang diberi biopestisida. Keadaan ini berarti bahwa penggunaan biopestisida racun labalaba Nephila sp. mampu menghasilkan nilai indeks dominansi yang sama bersama dengan pestisida sintetis. 


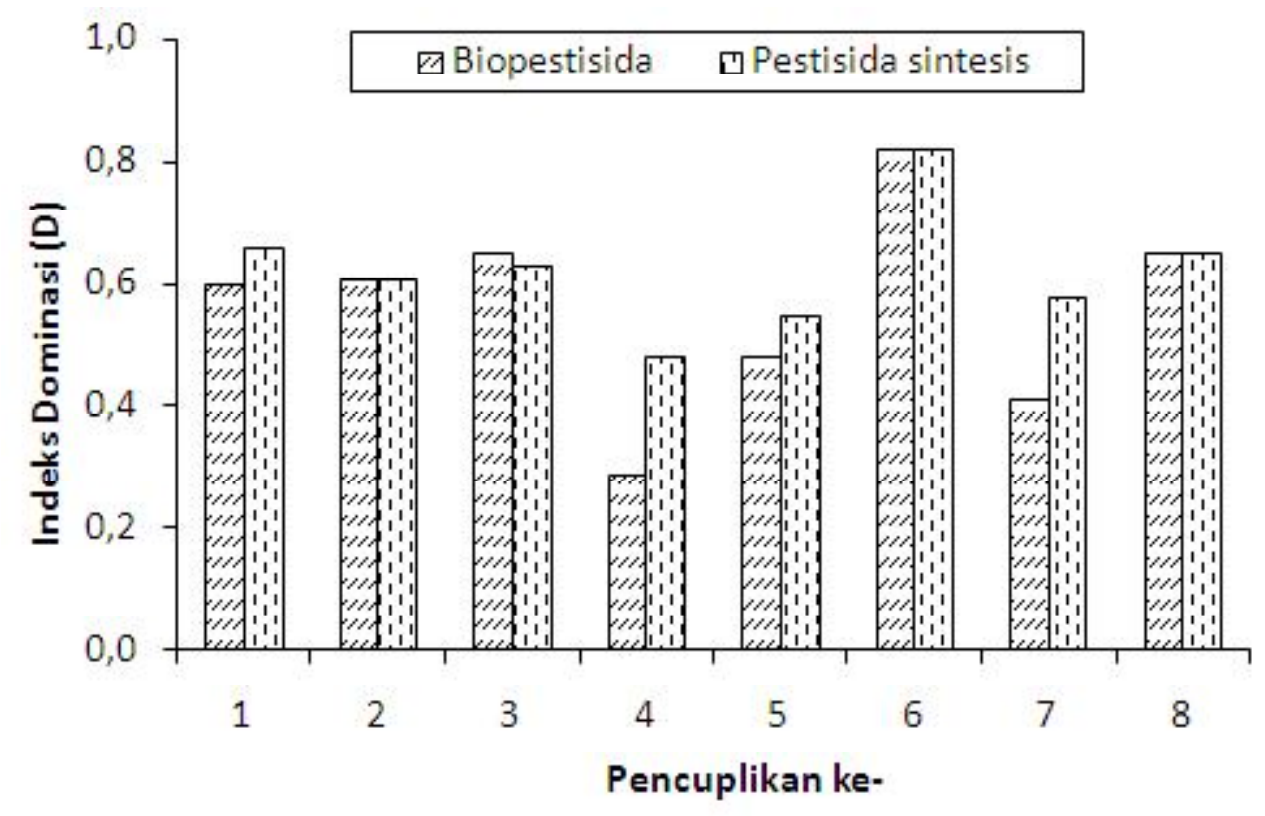

Gambar 3. Grafik fluktuasi indeks dominansi pada tanaman cabai yang diberi pestisida sintetis versus biopestisida.

Dengan mengetahui nilai indeks dominansi serangga dilingkungan tanaman sayuran, diharapkan agar kita dapat mendeteksi adanya gangguan terhadap lingkungan atau pencemaran, misalnya efek samping penggunaan pestisida sintetis dan zat kimia lainnya pada lingkungan dan biota bukan sasaran. Sebagaimana telah diketahui bahwa pencemaran lingkungan pertanian oleh pestisida sintetis telah menimbulkan beberapa akibat diantaranya yaitu resistensi serangga hama, timbulnya hama sekunder, adanya residu pada hasil pertanian yang di konsumsi, dan membunuh musuh-musuh alami hama yang merupakan komponen biotik penting dalam pengendalian serangga hama (Natawigena, 1989). Kenyataan-kenyataan tersebut di atas menunjukkan bahwa pengendalian hama secara sepihak, khususnya penggunaan pestisida sintetis bukan suatu pendekatan yang baik, tetapi membahayakan karena faktor lingkungan sebagai bagian dari sistem ekologi kurang diperhatikan (Sosromarsono, 1993).

\section{SIMPULAN}

Dari hasil penelitian telah diperoleh data tentang diversitas serangga pada pertanaman cabai yang diberi pestisida sintetis versus pertanaman cabai yang diberi biopestisida. Berdasarkan kekayaan jenisnya, pada pertanaman cabai yang diberi pestisida sintetis ditemukan 14 famili serangga. Pada pertanaman cabai yang diberi biopestisida terdapat 15 famili. Dilihat dari tingkat kesamarataan taksanya, pertanaman cabai yang diberi biopestisida cenderung lebih tinggi dibandingkan dengan pertanaman cabai yang diberi pestisida sintetis. Berdasarkan keragamannya, maka nilai yang lebih tinggi terdapat pada pertanaman cabai yang diberi biopestisida dibandingkan dengan yang diberi pestisida sintetis. Diversitas serangga pada ekosistem tanaman cabai yang diberi biopestisida maupun pada ekosistem tanaman cabai yang diberi pestisida sintetis sangat dipenganruhi oleh lingkungan karena menunjukkan nilai rata-rata indek Shannon Wiener $\left(\mathrm{H}^{\prime}\right)<1$.

\section{DAFTAR PUSTAKA}

Borror DJ, Triplehorn CA \& Johnson NF. 1992. Pengenalan Pelajaran Serangga Edisi keenam. Gadjah Mada University Press. Yogyakarta.

Cronquist A. 1981. An Integrated System of Classification of Flowering Plants. Columbia University Press, New York.

Dibiyantoro LHD. 1996. Kemangkusan agen hayati hasil temuan baru dalam PHT Thrips tabaci Lind pada Allium. Jurnal Hortikultura 6(4): 55-66.

Foelix RF. 1996. Biology of Spiders (Second edition). University Press, INC. and Geroge Thieme Verleg, Oxford.

Kardinan A. 2002. Pestisida Nabati: Ramuan dan Aplikasi. Penebar Swadaya, Jakarta. 
Klowden MJ. 2007. Physiological Systems in Insects second edition. Academic Press, Burlington.

Michael P. 1984. Ecological Method for Field and Laboratory Investigation. Tata McGraww-Hill Publishing Company Limited, New Delhi.

Maguran AE \& Hall. 1988. Ecological Diversity and Its Measurement. Princeton University Press, Princeton.

Natawigena H. 1989. Pestisida dan Kegunaannya. CV. Armico, Bandung.

Odum EP. 1993. Dasar-dasar Ekologi. Gadjah Mada University Press, Yogyakarta.

Ori M \& Ikeda H. 1998. Spider venoms and spiders toxins. J. Toxicol.-Toxin Reviews 17: 405-426.

Pedigo LP. 1999. Entomology and Pest Management Third Edition. Prentice-Hall, Englewood Cliffs, New Jersey.
Philip CR, Herbert DA, Kuhar TP, Reisig DD, Thomason WE \& Malone S. 2011.Fifty years of cereal leaf beetle in the U.S.:an update on its biology, management, and current research. $J$. Integr. Pest Management 2 (2):1-5.

Sosromarsono S. 1993. Pemanfaatan bahan alami dalam pengendalian hama terpadu. Makalah Seminar Pemanfaatan Bahan alami dalam Upaya Pengendalian Populasi Organisme Pengganggu Tanaman. Cisarua, 10-11 Agustus 1993.

Tan R. 2001. Golden Orb Web Spider Nephila maculata. http://www.naturia.per.sg/buloh/ inverts/nephila.htm. Diakses 15 Januari 2010. 